\title{
Reading and Writing in Graduation: Requirement or Pleasure?
}

\author{
Milena Ramos, Claus Dieter Stobäus, Maria Inês Côrte Victoria, \\ Juan José Mouriño Mosquera \\ Postgraduate Program in Education, Pontifical Chatolic University of Rio Grande do Sul, Porto Alegre, Brazil \\ Email: Stobaus@pucrs.br
}

Received 10 August 2014; revised 2 September 2014; accepted 11 September 2014

Copyright (C) 2014 by authors and Scientific Research Publishing Inc.

This work is licensed under the Creative Commons Attribution International License (CC BY). http://creativecommons.org/licenses/by/4.0/

(c) (;) Open Access

\section{Abstract}

This paper stems from discussions between the authors about the research survey Ramos held throughout the year 2013, focusing on research in the analysis of teaching practices considered positive, in order to create/foster a culture of reading and writing in Higher Education. Data collection for the study was conducted with 150 students from discipline Education and Children's Literature, which is developed during the third semester of Pedagogy Undergraduate (Faculty of Education) at Pontifical Catholic University of Rio Grande do Sul-PUCRS, of which 11 testimonies were selected intentionally, why they answered all questions. The theoretical framework is based on approaches that understand the issue of reading and writing as a commitment to be assumed by the university, teachers and students, in order to identify potential for this crop is established, as well as vantages and limitations that challenge to overcome. Qualitative analysis of content showed that empathy with the teacher contributed to the rapprochement of students with writing and reading, both technically and by delight; the scarcity of reading and writing in this Higher Education stage; the need to undertake a joint and collective work between students and their teachers to the practice of reading and writing is seen as a commitment from all disciplines; the need to improve these skills; and the need for a work aimed to scientific literacy in Graduation, for the welfare of students in the institution. At the final of the article we present some suggestions for the development of reading and writing in Higher Education.

\section{Keywords}

Reading, Writing, Higher Education, Student Welfare

\section{Introduction}

This article is the result of discussions between the authors, about the components of the research Ramos (2013), 
during their development, under the guidance of Stobäus, linked to the Search Line Person and Education, Program Graduate of the Pontifical Catholic University of Rio Grande do Sul-PUCRS, where she had the opportunity to work with pedagogy students at the discipline given by Maria Inês. Thus, the stage of the investigation was given in an undergraduate lecture room, within which the observations and data collected triggered exchange and sharing between the classroom teacher, graduate students and discussions both among themselves and with the supervisor of his dissertation. Such triangulation resulted in permanent motion learning by both, the teachers and the graduate students involved in the project.

\section{Methodology}

The intention of researching and deepen this theme arose from the performance of Ramos Master's degree in education, through observation and interaction with students of various levels of pedagogy, as a teacher of Portuguese Language, as well as revising texts about university and business. The experiences showed that factors such as familiarity with reading and writing, as well as the habit and the taste for exercise them, are somewhat rooted in the school environment.

In some contexts, teachers of Portuguese Language strives to focus on the job in developing these skills, but the fact is that even if the property do with technique and motivation, these efforts are sometimes not enough to effectively develop a real and constant writing and reading culture by students will be the following teachers, especially considering that other disciplines also, for various reasons, not as much as they could to stimulate interdisciplinary work involving writing and reading.

If students are struggling to develop their reading and writing during their training in Basic Education, one can imagine the obstacles they will face as they enter, until left Higher Education.

The relevance of the discussion is justified, among other things, by the way any limitations in the areas of reading and writing can be projected on the performance of students on graduation. After all, no one feels comfortable and able to learn when not mastered the minimum expected by the time they are studying, in case Higher Education, especially in reading and writing.

Accordingly, to investigate the students of Undergraduate Education provides a deeper look about the focus of the study, seeking thereby trying to unveil the setting in which these research was conducted in order to try to weave good inferences, wishing power contribute to the work of reading and writing, still in undergraduate, and therefore stimulating discussions with theoretical and practical about the most significant works in schools foundation.

The research subjects were students at the university enrolled in Pedagogy course, who were attending the discipline Children's Literature and Education, of which 11 testimonies were selected intentionally, why they answered all questions.

The study was approved by the Faculty of Education, at the Pontifical Catholic University of Rio Grande do Sul-PUCRS (n. 106/2013) Scientific Commission and the subjects participating signed a Consent Form, as well as names and images of participants were not used, so they are identified as subject $(1,2,3 \ldots)$ in the denomination of their speeches.

\section{Results and Discussion}

From the questions in the questionnaire used in the survey, it is known that this research focuses on the undergraduate students, so seemed to be essential to know which moments reading and writing are used, as well as the perception of the students about the meaning they give to them. Thus was asked to research subjects: in what moments you use reading and writing?

The following categories emerged: 1) First Contact with the Reading and Writing in the Undergraduate: Role of the Mediator; 2) Significant Moments in Reading and Writing Graduation; 3) Expectations and Feelings Awakened by the Graduate Reading and Writing; 4) Reading and Writing in Personal and Professional Sectors.

The analysis of the responses, quantitatively and qualitatively, can leave emerging categories described here, among them in particular answers about the feelings aroused by reading and writing in graduation. In this issue, we seek to focus on reports of feelings of students as they read and write, emphasizing, then, the person of the reader/writer in Higher Education, seeking to understand what arouses the welfare that student who reads and writes and what needs could be enhanced to your fingertips.

For this, the lines of research subjects were of great value for the analysis of many larger issues than to seek 
in research, as observed in the transcription of some of them, like the subject 1 , that highlights "use reading and written in graduation for personal notes, what I find most relevant classes. Notes, are sometimes reflections or even feelings".

In this regard, current studies have been devoted to emotions and feelings as well as aspects that influence the intellectual acquisitions, as well as highlights argues Damasio (2004) that every experience of our life is accompanied by some degree of emotion, especially in relation important social and personal problems. There is already a perception in the sense that they influence how much and how to learn and, respectively, in the actions of human beings. Thus, cognition is directly linked to emotion, so that without this work, hardly attain the cognitive part that permeates the entire education.

As Asensio, García Carrasco, Núñez Cubero \& Larrosa (2006: p. 23) says:

In recent years, we have been aware, including through publications that reached the general public, the work of some scientists about the dynamics of the emotional mind and its influence on human behavior. Fruits of that interest, rather than renewed, unpublished, by the emotions of current science has been, for example, the determination of some of the neural circuits involved in them, understanding how these dynamics that organize the body leads to certain affective states or how emotions affect cognition and behavior.

Thus, reading and writing go through these processes, and can say that the emotional part is directly reflected in the habits of reading and writing, skills for such in the disinhibition in making them, the taste developed, since this early school until graduation and even beyond that, i.e., it is necessary that the educator has possession of such information to enable a broad development of their students.

Therefore, we insist that reading and writing are the result of experimentation, experience and construction of each, as in addition to the skills, opportunities for development, positive testing, encouraging teachers with passion and truth, since reading and writing is part of their life too. From this statement one may think that writing for him/her, as it gives more motivated by academic assignments and practical "obligations". Not, therefore, of a written marked by the pleasure of being able to express yourself, to be able to put yourself in contact with each other and can also even, either a written prepared by/for personal enjoyment.

With regard to reading, the same guy first tells us that "the reading, do not like to perform in the classroom, I prefer an environment that gives me more solitude".

Remembering the purpose of this report, we seek to Asensio, García Carrasco, Núñez Cubero \& Larrosa (2006: p. 153) the concepts that appear in the dialogue with the testimony property in question:

When a field of knowledge is already learned and becomes automatic/habitual, can run somewhat independently of their affective and pleasurable value. However, experience shows that a person accustomed safer anticipates that the action they undertake is establishing a source of pleasure.

Thus, the processes of reading and writing of a student who dominates, takes pleasure in making them and took steps to improve their well developed before entering graduate, will occur during the course naturally, automatically, without suffering the block and prevent them from appropriating the knowledge, since reading and writing with property attributes are necessary for the proper performance in all disciplines.

According Asensio, García Carrasco Núñez Cubero \& Larrosa (2006), is precisely the difficulty with some knowledge that will hinder its improvement and will bring insecurity and block the pleasure that could be provided during execution. It fits perfectly in relation to reading and writing. That block students to read and write and do not take pleasure in them in Graduate need to be stimulated and feel at ease in order to acquire more security, which allows to develop and increasingly go-appropriating the read-write as possible acts for his person.

Then it can be inferred, at least from part of that testimony highlighted, as on the task of reading is of conditions so that the reading can be performed. But silence, nowadays, is that we have less. Time and silence are privileges for few. Then reflect on the importance of allocating spaces and systematize spaces for reading find a place in our current culture (as technologized and fleeting, full of "filling in spaces and times") as something fundamental to that reflection can occur, so that the development of ideas may be possible, finally, for the teacher to play its role as organizer of the times and spaces of learning in their teaching processes, in particular that its most genuine role: think and make you think.

Another point to be mentioned is perhaps at least on personal learning characteristics, as highlighted Stobäus \& Mosquera (1984), based on constructivist ideas of constructivism of Ausubel, that some students are more visual (learn by seeing, writing and performing syntheses possibly more graphically) and others are more auditory (listen to the subject, recall aurally, and soft music or even silence while learning can be important). Also worth remembering the moment socio-historical-political-professional and personal lives that the human being 
at every stage of their life cycle, highlighted by Mosquera (1987), in his book Vida Adulta (Adulthood) and more currently Nóvoa (2007), when highlights the evolution of personal and professional life of teachers.

As a kind of counterpoint, quoted subject 2, which tells us that "reading and writing as natural acts of who owns the culture of letters, a habit that I practice as a formula for reflection and manifestation of all that ails me and fascinates. [...] But reading and reflective writing is something that should be used in schools.

Here we might recall that Vygotsky (1999: p. 104) and said that learning is inherent to living beings, and we would add that, from amoeba to humans, all learned within nature, in our case in contextualization, and two of more relevant are the family environment and schooling.

The subject 2 also emphasizes that "the pedagogy course requires quite readings and often critical comments of the reading. [...]. I love to read. [...]. I also think unfeasible an educator who does not like to read as encourage children and young people if he himself does not read?

As Lajolo (1999: p.108):

The discussion about reading, especially about reading in a society that aims to democratize as begins saying that professionals most directly responsible for initiating the reading must be good readers. A teacher must love to read, need to read a lot, need to engage with what they read.

Thus, we can think here about the perception of student of Pedagogy about the importance of encouraging a love of reading as part of the teaching processes that result in good learning held by their teacher, is something commendable, it denotes that the student is convinced a reader as the teacher can encourage and influence their students, and very well may imitate, as highlighted Bandura (2008).

We realize in this category, which focuses on the feelings aroused in the reader/writer in graduation as well differentiated responses, such as the preference of reading in solitude, written in class awakened thoughts and feelings in class, for others reading as something natural and quiet by longer a person more accustomed to texts.

As highlighted by the student 3 in his speech,

The freedom to write in our work posted on Moodle and works hand delivered is our biggest exercise in reading and writing here at graduation. [...] Power experience the theory and practice at the same time is quite enlightening and motivating as well how to make us feel safe construction of new knowledge. Discover who is capable and that the person (teacher) believes in his ability and commitment is very pleasurable and meaningful. Writing and reading is constant and necessary. I feel valued as a student and do not have anything better than this.

Despite this freedom to write, despite being aware of the need and importance of the required readings for the student's education at undergraduate as well as the school, the university needs to be aware of the importance of training and maintenance of the reader, we need to least some freedom of choice in their reading, so not only to reduce the mandatory.

As Lajolo (1999: p. 109) says:

It is also important to note that the practice of reading sponsored by the school must occur within a maximum freedom. Reading becomes free only when it relates, at least in early stages of learning, pleasure or disgust of each reader for each book. That is, when you do not oblige a whole class reading the same book, on the grounds that such a book is appropriate for the age group of those students, or that it is a topic that interests that type of child.

So, thinking about a transformation of the reader and therefore the writer at the university, we understand that, beyond the school in the early years, the university must allow some freedom of choice of readings that prime by the scope of qualified player. We emphasize that, in many cases, the initial development of the competences may give (more) up at the university, if it has not occurred by that before, must be developed at these stage.

Here also highlight the feelings that subject 3 regarding teacher discipline, especially the relationship between theory and practice provided by the teacher, related to writing and reading. The fact that the incentive occurs, positively encouraging student's self-esteem, as when he says "if you can find that" and later "as a student feel valued and have nothing better than this", denote the difference that gave these classes Education and Children's Literature, and how much to contribute beyond the content already proposed by discipline, but for the integral formation of the reader and producer of subject texts.

This is one of the most constructive elements in the classroom, ratifying the concepts of Mosquera, Stobäus, \& Herminio (2006), who pointed out that, when used as elements of positive motivation, reinforcements to realistically raise the self-image and self-esteem of their students, there are exercising very important roles for a teacher who wants and realizes that their student "from growing and appear" for himself, for his (better) compe- 
tences and qualities. Especially when dealing with issues related to Higher Education, the university (Mosquera \& Stobäus, 2008).

We believe also that it is important to emphasize how positive are the words used by the subject 3 to explain their feelings regarding the use of reading and writing at undergraduate, specifically in the discipline, as highlighted in attributes: enlightening, motivating, security, discover, construction, pleasurable, meaningful, valued. All of these words carry with them an atmosphere of "good and positive things", important feelings that contribute to the welfare of the student and, of course, provide an education of the highest quality and best results.

Therefore, as Mosquera \& Stobäus (2008: p. 108):

We believe that in school environments, it is necessary to develop more positive and realistic aspects of selfimage and self-esteem, because the education system interacts intensively for the development of their own person and sociocultural dimensions.

We also emphasize that these statements attributed to class and the teacher confirm and corroborate the descriptions previously did about what we observed during teaching and monitoring of the groups in the given discipline, which indicates that students are also attentive and eager for classes and teachers contribute beyond the transmission of content, application and proof of completion of a course more to the end of the semester.

Therefore, as Seligman (2011: p. 157), author and researcher focusing on Positive Psychology, "positive emotions shed light on things that are particularly good for us or that are have the potential to run well", so that classes tend to be increasingly a hit with students, leaving them free to develop and qualify their reads and writes more smoothly, because we realize that they are already engrossed in positive emotions and, from that, the taste and desire by read and write only tend to widen. Also according to him:

If you feel admiration for someone, it means you think that person has demonstrated great skill or talent in something. As a model of success (at least in this field), if you watch this person, you may notice how she performs this ability.

Through the words of the author, we seek to understand the admiration for the classes the teacher by the students, and the enthusiasm with which conducts its discipline, and we conclude that, for all these characteristics, the teacher also infects the students with their example. They can sense his passion for books, writing and recognize the ability of students at it, so that it becomes a successful example to be followed. And even most already being in early adulthood, others already in their mid, good examples are very excited contagious, and we believe that act as a balm that eases and facilitates the day to day running around, working on shift integral, over the university at night, setting the third shift of the day, as already mentioned, showing that it pays to be there to acquire new knowledge.

In the next two lines we have more elements, as "I use writing and reading ever. In letters mandatory readings end up becoming part of everyday life" (subject 10), and "always use reading and writing. I believe we are always enjoyable, since I end up meeting new readings, increasing my vocabulary" (subject 11).

The subject 5 also highlights that "PUCRS should take a Reading Dynamics and Memory course to help us read and interpret as soon as possible [...]. Would be good for everyone, because we would write better if we understood better the texts within this overwhelming space of each semester".

From this, we believe that this ability to appropriate reading and writing needs work increasingly in students of Higher Education, preferably by all teachers to contribute to your education and professional qualifications. And, although stimulated and improved, can yield great results, as we witness the progress of the groups at the end of each semester. Hence the importance of assessing how built and still build the skills of reading and writing of these students graduate, find out how mediation was the reading of students and who brokered, and also, what are the relevant moments of reading and writing students.

This study revealed that the mediation of reading and writing took place mainly by family, school, or even at the university. Where was the family, the parents were not always the mediators were uncles and grandparents, but realize that some speeches indicated the implicit wish that had been the parents, when they say that this was not done by them. In the school, were some teachers of the Elementary and High School.

And for some, this mediation was to occur only by the university teachers, through the read requests and written works. What denotes the possibility, and say more, the responsibility that teachers of Higher Education has to instigate, develop, work and expand the reading and writing of their students, since, for some, this familiarity may happen only in graduation.

The relevant time reading and writing, the highlight was the coming demands of the university, almost all placed as paramount, and, for some, the only moments to read and write. On these readings and writings, stu- 
dents were pressured by the amount of polygraph readings, books and papers about for all subjects, which would hinder or impede the time for other readings of own choice.

Check the yearning for can read, memorize and be able to interpret "as soon as possible" ("ASAP"), highlighting the feeling that there is too much demand and not enough time to account for the readings and work to be done at the university, as well as shows that students perceive themselves who need to better understand and write texts distributed.

From what we see, the student already has this design worked by positive experiences in the classroom, because you only have the understanding that it would be good a course focused on reading, for example, a student who believes in its efficacy, otherwise the student wants to "right distance", even courses that address subjects such as reading and writing.

But on the other hand, one should not overlook the issue that the faster the student read by necessity, less able to absorb this reading, which may be less qualified. If there is any element of this assessment should also point out that "haste is the enemy of perfection", also in the area of reading and writing.

To Lajolo (1999: p. 105):

The reading activity, which, in its origins, was individual and reflective (as opposed to collective, volatile and unrecoverable character of oral poets and storytellers), today became fast consumption of the text, in which dynamic reading to be profitable, you have to grow old quickly, constantly creating the need for new texts.

It is worth noting, comment the author, which we seek to exemplify and emphasize that reading skills and comprehension, whether express are far beyond the classroom, and constitute a kind of knowledge that the student, as well of need in all disciplines, will lead to life and make a difference in their world view and in the ways that follow, or as follow. Here, we recall the speech of Mosquera (2012), that "Education is not only to teach, is to form". Whose words illustrate very well what was previously expressed.

Moreover, even for those who have completed graduation, which are already placed in their profession, the result would be much better if their education had been based on skills readers, even to read magazines with wide circulation and more directed to the public service, executive, scientific, finally, we must have such capabilities to not only well enjoy and understand the text, to discern what, everything that was read is valid and usable for their views.

Another interesting aspect is the deepening of Vygotsky's theory of on the Proximal Development Zone, which could yield great fruits of work considering that their studies show that it is always possible to instigate the student, even though he still is in the development process, for example, the acquisition of reading, writing and understanding the text. Would be a possibility that we are "planting" for the future, because "the development curve does not match the curve of school learning in general learning precedes development", by Vygotsky (1999: p. 127).

This type of work in the classroom allows for greater interaction between students of different skill levels, helping each go through being encouraged to think of being with each other, with the mediation of the teacher, going to be interested to read write.

Activities such scope can be developed in all disciplines in order to contribute to the development of the students, avoiding compartmentalized and reduced to knowledge of one area or another in Education, but must enable teachers to recognize their importance in participating in the training full of his students.

The reflection together allowed, from the category reported here, especially with regard to feelings aroused by reading and writing to understand how students feel about these activities during lectures in their Undergraduate Program, would like to see how these moments, so that the responses focused on the person of the reader and writer, in order to understand what arouses the welfare that student to read and write and what needs to be improved to achieve this.

Some of them, more accustomed to the exercises, referred to reading and writing as something natural, which is done with ease; others liked to use writing to write down everything they could during class: content, feelings and thoughts aroused by the readings.

Others expressed prefer to read alone and away "far from the classroom", which denotes a certain uneasiness on the subject, since it is just impossible to read at home because all classes have demands some kind of reading time for which, if the student is not feeling peaceful in doing so, will not reach the level of detail needed to absorb the contents of the desired shape, and the need to interact with their classmates and their teacher, factors to be taken into account for its processes learning, which will impact on your future education when teaching.

Still, some expressed feeling good with the freedom to write and post on Moodle for jobs in person, express- 
ing their ideas. We emphasize that the students made a point of stressing how they feel well with the incentives and motivation they received from a teacher, who were freer to read and write even by feel capable and valued.

Many other positive words used to refer to the development of the discipline, the contents and form of work the teacher, as well as enlightening, motivating, provide security, provide the figure, construction, be pleasurable, meaningful, valuing, evidencing that are having positive experiences of well-being, especially with respect to reading and writing in the discipline.

\section{Conclusion}

We would like to reiterate some elements that we believe are likely to be developed within this perspective of improvement in reading and writing, through, for example:

1) Contextualizing, that is, try to gather two facets apparently dissociated: Reality itself, with his hand over "ground", objective and straightforward, and fantasy, with their creative side, suspended in "another world" but "reaches in and back away".

2) The "hours of speech", where, for example, groups of no more than four pupils, bringing reading and personal development advance elected materials, meet and expose between them, so that they can select the best and present If the large group, reducing the presence of "timidity and fear" exposure in public, and may even serve as auxiliary of teacher evaluation.

3) Present and encourage students to read for enjoyment, because its benefits for both student and professional framework for personal Sarong as a source of well-being and pleasure.

4) Provide in classroom activities that demonstrate how the readings also contribute to the improvement of writing, through the acquisition of a richer and more abundant vocabulary, which will be reflected in assessments of disciplines, the day-to-day work and various situations in which undergraduates use the writing.

5) Working with knowledge, skills and attitudes, including respect for the different and diverse, with the possibility of its expression, so that it becomes more understandable and is sprawling, so that many more have access to them.

As final words of encouragement, from this perspective, we believe that it is for teachers of undergraduate, as a whole and purposely try to empower their students to improve in reading and writing, creating and fostering a culture reader and producer of texts in the classroom, as a way to introduce reading and writing as necessary for the world of work skills, but also to the delight and enjoyment that we all have rights.

\section{References}

Bandura, A. (2008). Aprendizagem social e cognitiva. Porto Alegre: Artmed. (Original (1975). Social Learning \& Personality Development. NJ: Holt, Rinehart \& Winston, INC.)

Lajolo, M. (1999). Do mundo da leitura para a leitura do mundo. São Paulo: Ática.

Mosquera, J. J. M. (1987). Vida adulta: Personalidade e desenvolvimento (3rd ed.). Porto Alegre: Sulina.

Mosquera, J. J. M. (2012). Teoria da Educação. Porto Alegre: Disciplina do Curso de Pós-Graduação em Educação da PUCRS (Comunicação oral).

Mosquera, J. J. M., \& Stobäus, C. D. (2008). Auto-imagem, auto-estima e auto-realização na universidade. In D. Enricone (Org.), A docência na educação superior: Sete olhares (2nd ed., pp. 111-130). Porto Alegre: EdiPUCRS.

Mosquera, J. J. M., Stobäus, C. D., Jesus, S. N. de, \& Hermínio, C. I. (2006). Universidade: Auto-imagem, auto-estima e auto-realização. UNI Revista, 1, 1-13.

Mosquera, J. M. M., \& Stobäus, C. D. (1984). Educação para a Saùde (2nd ed.). Porto Alegre: D. C. Luzzatto.

Nóvoa, A. (2007). Vidas de professores (2nd ed.). Porto: Porto Editora.

Ramos, M. (2013). A pessoa do leitor/escritor: Uma proposta de educação para o desenvolvimento de habilidades. Dissertação (Mestrado em Educação)—Faculdade de Educação da PUCRS (Master Degree Thesis, Faculty of Education).

Seligman, M. E. P. (2011). Florescer: Uma nova compreensão sobre a natureza da felicidade e do bem-estar. Rio de Janeiro: Objetiva. (Original (2011). Flourish: A Visionary New Understanding of Happiness and Well-Being. New York: Free Press.)

Vygotsky, L. (1999). Pensamento e Linguagem. São Paulo: Martins Fontes. (Original (1986) Thought and Language. Newly Revised, Translated, and Edited by Alex Kozulin, Cambridge, Massachusetts: The MIT Press.) 
Scientific Research Publishing (SCIRP) is one of the largest Open Access journal publishers. It is currently publishing more than 200 open access, online, peer-reviewed journals covering a wide range of academic disciplines. SCIRP serves the worldwide academic communities and contributes to the progress and application of science with its publication.

Other selected journals from SCIRP are listed as below. Submit your manuscript to us via either submit@scirp.org or Online Submission Portal.
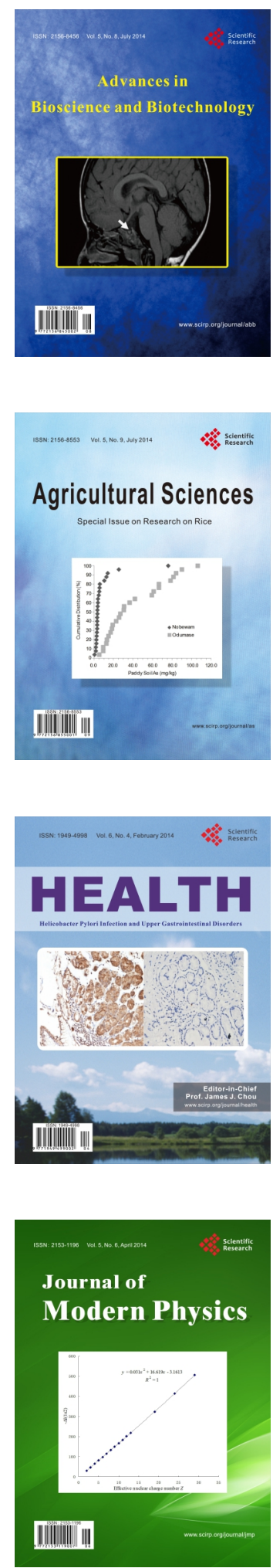
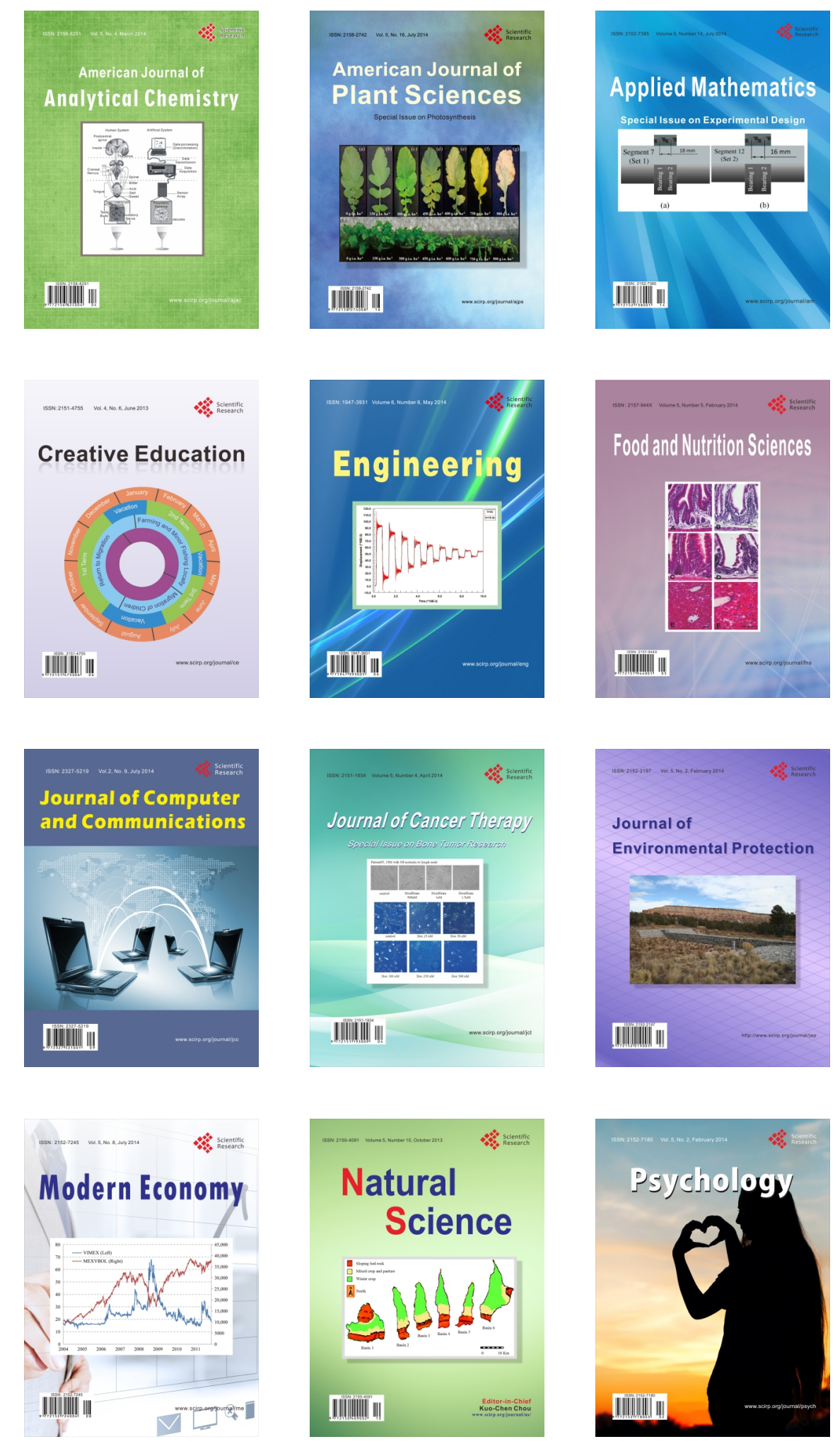